\title{
El dispositivo del dron: entre la vigilancia securitaria y la necropolítica
}

\author{
Drones: Between Security Surveillance and \\ Necro-politics
}

\author{
Ignacio Mendiola-Gonzalo (i) http://orcid.org/0000-0002-2703-5743 \\ Universidad del País Vasco, España, ignacio.mendiola@ehu.eus
}

\begin{abstract}
Moving away from the growing techno-scientific fascination embodied by the drone, the main aim is to analyze the role played by this device in the context of the current security surveillance. Following to a great extent the conceptual approaches coming from critical security studies, we will address issues that refer to the redefinition of the surveillance provided by the scopic power of the drone, the military-police logics in which it is immersed in order to detect what has been defined as a threat and, finally, to the specific geographical reconfiguration of the sovereign power the drone activates within the framework of security surveillance. It will be concluded that, opposing the surgical warfare discourse that legitimizes the drone via its techno-scientific accuracy potential, this device reproduces a necro-political logic that must be exhibited and questioned from the violence it causes.
\end{abstract}

Key words: drone, dispositive, security, surveillance, necro-politics.

Resumen: El objetivo central del presente artículo es analizar el papel que juega el dron en el contexto de la actual vigilancia securitaria. Con base en gran parte de los planteamientos conceptuales de los estudios críticos de la seguridad, se abordarán cuestiones que remiten a la redefinición de la vigilancia que depara el poder escópico del dron, a las lógicas bélico-policiales en las cuales está inmerso, para detectar lo que queda definido como amenaza y, por último, a la específica reconfiguración geográfica del poder soberano que el dron activa en el marco de la vigilancia securitaria. Se concluirá que, frente al discurso de guerra quirúrgica que legitima al dron a través de su potencial tecnocientífico de precisión, este dispositivo reproduce una lógica necropolítica que ha de ser expuesta y cuestionada desde la violencia que ocasiona.

Palabras clave: dron, dispositivo, seguridad, vigilancia, necropolítica. 


\section{Introducción}

En su análisis de la figura del panóptico, Foucault (1989: 16) enuncia un rasgo crucial que actúa como mecanismo desencadenante de todo un elenco de prácticas sociales cuyo recorrido es posible rastrear hasta nuestro presente: "Un miedo obsesivo ha recorrido la segunda mitad del siglo XVIII: el espacio oscuro, la pantalla de oscuridad que impide la entera visibilidad de las cosas, las gentes, las verdades". Se enuncia aquí un deseo, afincado en el núcleo mismo de la modernidad, que ha sido parte esencial del afán por articular un régimen de observación, que, en última instancia, torne el conjunto de la sociedad en una trama transparente donde se disuelva toda opacidad y oscuridad, con el fin de obtener una realidad visible y legible.

Una mirada que ve todo, omnisciente, "dominadora y vigilante", que revierte la sombra en luz, posibilita "una visibilidad universal” y que puede, cuando todo ello se cumplimente, subsumir lo que ha quedado atrapado por esa luz en "un orden riguroso y meticuloso". Este sueño es un sueño que no solo quiere activar meros mecanismos de vigilancia que recorran el orden social; en un sentido más profundo, es un sueño que quiere saber y conocer aquello que se hace y se pudiera hacer, un saber que se anticipa para prevenir y regular.

Cabe añadir que este anhelo de una visibilidad universal encarna un impulso que necesariamente se reactualiza de un modo continuado, que no puede conformarse con la visibilidad obtenida en un momento dado, porque siempre pudiera haber resquicios que la cortocircuitan, que habilitan zonas de sombra en donde el poder todavía no llega a ver lo que ahí se está suscitando; por ello, la exigencia de esa sociedad transparente, el exhorto a esa visibilidad universal, no es sino la constatación de que no hay descanso, de que esa mirada que quiere ver todo está encarnada en un ojo que no puede cerrarse.

No cabe duda de que la imbricación entre visibilidad y poder ha constituido el trasfondo de todo un campo de análisis en el cual se podrían rastrear aspectos como la reconstrucción sociohistórica de los discursos y prácticas que han venido a legitimar la necesidad de articular esa mirada omnisciente (Harcourt, 2016; Lyon, 1995), las diversas tecnologías a través de las cuales se han ido implementando procesos de identificación de las personas y sus actividades (Abot y Denis, 2011; Lyon, 1995; Sekula, 1986), los mecanismos político-punitivos que se coligen de las prácticas de prevención, regulación y castigo subsumidas en el saber-poder que acompaña a la vigilancia (Foucault, 1990), o, por último, las estrategias de resistencia desplegadas por 
los sujetos para poder seguir recreando ámbitos opacos donde la mirada del poder no acaba de penetrar (de Certeau, 1996; Harcourt, 2016).

Desde el escenario que se abre en este campo multidimensional, con la producción, legitimación, gestión y vivencia de un saber-poder vigilante, la reflexión que aquí se expone no pretende tanto ahondar con detenimiento en alguno de estos ejes analíticos cuanto explorar el modo como las temáticas que ahí se suscitan se solapan entre sí en un dispositivo concreto de vigilancia, el cual está adquiriendo una creciente relevancia social.

Desde la invitación foucaultiana a pensar lo actual, esto es, a indagar críticamente en los regímenes de verdad y poder que dan forma a la cotidianidad que habitamos, se focalizará la atención en el dispositivo que se articula en torno al dron, los aviones no tripulados que pueden ser dirigidos por control remoto. El dron, imbuido de una creciente fascinación política, mediática y militar, se convierte en este inicio del siglo XXI en la reactualización casi paradigmática de ese antiguo sueño de una sociedad diáfana, donde el terreno oscuro de la sombra queda iluminado por una mirada irrestricta.

Es esta fascinación y la propia práctica del dron lo que aquí será interrogado. Es necesario añadir que hay todo un desarrollo de investigaciones tecnológicas conducentes a confeccionar drones con campos de aplicación distintos a los que aquí se hace referencia: su uso en el rescate de personas (o cadáveres) ubicadas en zonas de difícil acceso o en el monitoreo de espacios que han sufrido desastres naturales constituyen ámbitos de aplicación con un indudable potencial de ayuda. Pero no es este el terreno donde se moverá el presente estudio.

En el marco de esta reflexión, el foco estará únicamente en la irrupción del dron en tanto que parte de un entramado bélico-policial que lo utiliza para detectar aquello que se lee en clave de amenaza y, eventualmente, para actuar sobre ello. Y, más en concreto, aun cuando ello todavía no sea enteramente desligable de lo policial, se pondrá el peso de la reflexión en la proyección bélica del dron. Este, y no otro, es el dron que aquí se interrogará y problematizará.

El uso de aviones no tripulados en tareas de vigilancia durante conflictos bélicos ya había sido probado durante el siglo XX, y más adelante, en los inicios del siglo XXI, en el marco del conflicto entre Israel y Palestina (Shaw, 2016). En todo caso, y para los efectos de esta reflexión, el contexto sociopolítico que más afecta e impregna el desarrollo del dron como parte de un entramado bélico es el que se desata tras los atentados de las Torres Gemelas, la denominada "Guerra contra el Terror".

En este marco espacio-temporal, el inicio puede datarse en octubre de 2001, cuando comienzan en Afganistán los ataques de drones armados que 
pueden disparar misiles contra objetivos fijados por las cámaras del dron. A partir de ese momento, el uso de los drones militares, conocidos como MQ-1B Predator y MQ-9 Reaper, iniciará una escalada muy significativa que camina en paralelo a una profunda alteración en la forma de concebir y practicar la propia guerra (Blackmore, 2005).

Con el fin de desbrozar el dispositivo del dron, se propone un recorrido analítico por tres ejes interconectados: la visibilidad, la vigilancia securitaria y la necropolítica. Estos ejes -abordados de forma progresiva en las tres secciones siguientes - tienen como objeto analizar críticamente el régimen de visibilidad que el dron (re)produce, el modo como este se encuentra inscrito en un régimen de saber que se articula en torno a la vigilancia securitaria, y, por último, la concreción de todo ello en una serie de prácticas bélicas que producen la (exposición a la) muerte. No se está, por ello, ante ejes autónomos sino ante dimensiones que se entrecruzan y se retroalimentan, confiriendo unas señas de distinción específicas al dron empleado en contextos bélicos.

\section{El poder y la mirada: más allá de la fascinación fetichista}

El punto de partida de este recorrido pasa necesariamente por impugnar todo atisbo de fascinación que la mirada irrestricta del dron pudiera deparar. Y como paso previo, inexcusable, cabe recordar que no hay una mirada ingenua, neutra, que pudiera adentrarse de un modo objetivo en la realidad, para volver narrando aquello que antes permanecía oculto.

Esa mirada tan solo vendría a reproducir los rescoldos de una epistemología clásica anclada en el ocularcentrismo, que reproduce el truco divino de un ojo desvelador de lo que permanecía oculto (Haraway, 1995); un ojo que dejando atrás las distorsiones que el cuerpo y el espacio pudieran acarrear, se encumbra como legítimo habitante de la anhelada objetividad. Esa mirada omnisciente se presentaría, en definitiva, como una mirada limpia, límpida, que ha llegado a ese mirar porque ha silenciado el contexto del sujeto que observa, desencadenando así una suerte de mirada descorporeizada que ve sin decir desde dónde se ve, al tiempo que oculta el proceso de producción de la mirada misma.

La crítica epistemológica de este acercamiento se ha realizado de un modo profuso desde distintos ámbitos filosóficos, socioantropológicos y tecnocientíficos, y no es necesario reproducir aquí todo ese trasfondo. El interés aquí es resaltar la importancia de un elemento seminal que está contenido en la crítica de Haraway y que la teórica de la cultura visual de Bal 
(2016: 32) enuncia de un modo contundente: "El acto de mirar está anclado en el cuerpo y, por tanto, es profundamente 'impuro"; es decir, toda mirada emerge desde un contexto corporal, espacial, que afecta irremediablemente al modo como se mira, a lo que se observa, a las imágenes que se producen y a la forma misma como esas imágenes, que interactúan entre sí, son leídas.

Al trasladar esto al presente ámbito concreto de análisis, cabe decir que el abandono de la fascinación que el dron desencadena en tanto mirada ininterrumpida, requiere poner de manifiesto la producción misma del régimen de visibilidad desde el cual emerge la mirada drónica teniendo presente que dicho régimen acontece en unos espacios, en unos contextos que condicionan la forma y el ejercicio de la mirada; es decir, la mirada drónica es el efecto no neutral de algo que la precede y la acompaña, o dicho en términos más pertinentes para la aproximación teórico-analítica del enfoque aquí desplegado: la mirada precisa ser espacializada, reubicada en la red sociotécnica que sienta sus condiciones de posibilidad.

El énfasis puesto por Lefebvre (2013) en torno a la necesidad de concebir lo social como un entramado de prácticas espacializadas y espacializándose, actúa como un trasfondo conceptual que posibilita contextualizar al dron a modo de una red sociotécnica topológicamente compleja.

Esta afirmación requiere ya de una serie de clarificaciones para adentrarse en la complejidad del dron. Hablar en términos de una red sociotécnica supone admitir que el dron no existe en sí mismo, sino como parte integrante de un entramado heterogéneo en donde actores humanos y no humanos se ponen en relación. En este sentido, el dron puede ser leído, atendiendo a las sugerencias provenientes de la sociología de la traducción (Latour, 2008), como un actor-red; esto es, un nodo que posee ramificaciones de diverso signo (tecnológicas, políticas, económicas, discursivas, espaciales), que se condensan en esta forma peculiar de avión no tripulado.

Visto desde esta perspectiva, el dron es ontológicamente indisociable de las relaciones con actores humanos y no humanos que lo posibilitan. Dicho con otras palabras: la figura del actor-red pretende respetar la heterogeneidad constitutiva de lo social, las conexiones que se trazan y que, en virtud de la forma como se conforman, confieren distintividad a las singularidades emergentes (sean humanos o no), y por ello el actor-red en modo alguno preexiste a esa trama de relaciones, pues es una concreción de las mismas, el efecto dinámico y cambiante de esa heterogeneidad subyacente y constituyente.

Sugerir que el dron es un actor-red, un ensamblaje de humanos y no humanos, tal y como desarrolla pertinentemente Holmqvist (2013), requiere alejarse de todo atisbo de fascinación y cosificación para adentrarse 
en su arquitectura constitutiva y en su performatividad, en las geografías en las cuales está inmerso y que (re)produce. La mirada se aleja aquí de manera irremediable de un halo de omnisciencia para proyectarse como efecto o práctica de esa red sociotécnica mediada por relaciones de diversa naturaleza.

Se puede enunciar, para clarificar la reflexión anterior, algunos de los elementos de esa red, la heterogeneidad desde la que irrumpe el dron: la trama científico-militar de investigación que recibe financiación pública para su desarrollo tecnológico (con las crecientes sinergias desatadas entre lo civil y lo militar), la red de bases militares que precisa para operar (ya sea en tierra o en mar a través de portaaviones), todo el conjunto de actores que precisa para mantener su persistente mirada (los pilotos de drones ubicados en Estados Unidos, pero también todo el personal militar desplegado en distintos lugares y que son necesarios para mantener la logística del dron), la posición geográfica de los distintos instrumentos tecnológicos que posibilitan la recepción y distribución de las imágenes que capta el dron (en donde destaca, por ejemplo, la centralidad de la base militar de Ramstein en Alemania), la conexión del dron con otros dispositivos de vigilancia (aquellos que operan sobre el seguimiento informático de las comunicaciones) o, por último, el propio desplazamiento geográfico del dron en tanto arma militar que es comercializada (Frew, 2018).

Todo este ensamblaje maquínico que enhebra geografías y actores humanos y no humanos de diversa naturaleza muestra, cuando es recorrido en su multiplicidad constitutiva, lo que la fascinación fetichista oculta. Pero esto es solo el primer paso. Es necesario ir más allá del hecho de rescatar la heterogeneidad subyacente al dron, las redes en la cuales está inmerso y que al mismo tiempo (re)produce.

Y este ir más allá pasa, en gran medida, por contextualizar las redes que el dron teje en un escenario sociopolítico, el cual demanda la articulación de un régimen de visibilidad desde donde borrar la opacidad que pudiera existir en lo social: ello tiene un sustrato sociotécnico, pero este es indisociable de un régimen discursivo que enuncia la exigencia creciente de una sociedad transparente, y es aquí donde se cree más fértil la idea de dispositivo en la acepción de Foucault, toda vez que ahí se recogen, con mayor nitidez, las dimensiones simbólicas y materiales de la espacialidad de lo social, las relaciones de poder que lo conforman y los procesos de subjetivación que desde ahí se conforman, aspectos que en la aproximación de la sociología de la traducción poseen un menor desarrollo. 
Cabe recordar la definición sugerida por Foucault (1985:128):

Un conjunto decididamente heterogéneo que incluye discursos, instituciones, instalaciones arquitectónicas, decisiones reglamentarias, leyes, medidas administrativas, enunciados científicos, proposiciones filosóficas, morales, filantrópicas, en resumen: los elementos del dispositivo pertenecen tanto a lo dicho como a lo no dicho. El dispositivo es la red que puede establecerse entre esos elementos.

El interés en esta investigación es ver el dron como un dispositivo que enhebra niveles de lo social distintos, una suerte de efecto performativo de una red heterogénea que lo posibilita, de una trama tecnodiscursiva, de un entramado político-científico-jurídico que actúa como una red de relaciones conectando actores y espacios diversos; relaciones de poder que inciden sobre la población articulando lo que Arteaga-Botello (2016), en un sentido foucaultiano, denomina tecnología para la gubernamentalidad. Se estaría así ante un dispositivo drónico multidimensional que condensa en sí mismo toda una forma de entender e incidir en el mundo. Lógicamente, y en virtud de esa misma multidimensionalidad enunciada, habría una multiplicidad de elementos susceptibles de ser desarrollados, pero la argumentación aquí esbozada, como ya se ha sugerido al inicio, pretende articular una trama teórico-conceptual articulada en torno a la visibilidad, la vigilancia securitaria y la necropolítica, con el fin de pensar desde ahí la especificidad del dron bélico-policial.

Las consideraciones previas, conducentes a la reconceptualización del dron, como dispositivo, eran necesarias para alejar la cuestión de la visibilidad de cualquier resonancia autorreferencial y posicionarla en un contexto tecnopolítico-discursivo que anhela la mirada irrestricta que el dron acomete. Este reposicionamiento de la visibilidad está enunciado con suma nitidez en Jonathan Crary, el teórico de la cultura visual: "Los dispositivos ópticos en cuestión, de manera significativa, son puntos de intersección en los que los discursos filosóficos, científicos y estéticos se solapan con técnicas mecánicas, requerimientos institucionales y fuerzas socioeconómicas" (Crary, 2008: 24).

De la mirada en sí, cosificada y abstraída de sus condiciones de posibilidad, se pasa a la producción de un régimen de visibilidad que produce, moviliza e interpreta las imágenes ahí generadas, asumiendo en todo momento la espacialidad de la mirada, ya sea en su proyección corporal (se mira desde y con el cuerpo, lo cual comporta que el mirar, como sugiere Bal (2016), sea, desde el inicio mismo, sinestésico), discursiva (el ordenamiento simbólico de unos espacios que legitiman la necesidad de producir una determinada imagen), tecnológica (la dimensión maquínica de toda imagen producida) y geográfica (los distintos espacios que son puestos en relación para producir, 
transmitir y visualizar unas determinadas imágenes). Estas sucintas consideraciones trasladan desde el imaginario de una mirada que observa negando su espacialidad constitutiva, hacia el contexto específico que permea toda producción de imágenes en un continuo geográfico-corporal.

Si uno se ubica en este planteamiento, se aleja definitivamente de la "metafísica del dron" (Noys, 2015), para indagar en la tecnopolítica de la visibilidad que el dron desencadena. Aquí es donde comienza el desplazamiento hacia el segundo eje -la vigilancia securitaria- de la tríada que vertebra esta reflexión, al ser necesario interrogar aquello que alienta el poder óptico del dron, esa mirada ininterrumpida que, como plantea Chamayou (2016: 43), quiere ver todo y todo el tiempo. En cierto sentido, esta imagen resuena con el dispositivo clave del poder disciplinar que Foucault (1990) proyecta en el panóptico, como si el dron fuera, en última instancia, una suerte de panóptico móvil. Pero las diferencias son notables. No solo porque el panóptico está pensado para operar en un espacio delimitado y subsumido en un aparato institucional que busca reproducir un saber concernido con esa institución, sino porque la visibilidad del dron actúa, por el contrario, en lo abierto, en un ámbito móvil y cambiante, no previamente fijado.

Hay otra diferencia que merece ser enfatizada. El panóptico busca un cuerpo dócil que asume el saber del marco institucional sobre el cual se proyecta; mientras tanto, el dron busca, antes que nada, capturar los cuerpos; es decir, el poder óptico del dron no busca necesariamente la instauración de una nueva moral, sino el control del espacio, de las prácticas que allí se ponen en funcionamiento, de los movimientos que se activan: la vigilancia drónica no anhela el cuerpo dócil (acaso busca el cuerpo atemorizado al desatar el miedo a un posible ataque), sino el cuerpo visible en su recorrido espacial, la exposición de los cuerpos, su aprehensión en un régimen visual sin que obligatoriamente importe que el sujeto capturado en una imagen deba interiorizar una determinada moral.

En este sentido, la mirada drónica se proyecta sobre los espacios, pero es sobre todo una mirada sobre los cuerpos que habitan o transitan por esos espacios, sobre los detalles, lo ínfimo, allí donde se puede leer la huella de una eventual sospecha. El dron toma del panóptico el sueño de la transparencia y la preocupación por lo nimio; sin embargo, igualmente se aleja de este al pretender, más que el sujeto dócil, la regulación de los espacios y la captura de los movimientos.

La visibilidad pretendida por el dron, su tecnopolítica, opera a modo de un engranaje intersticial que imbrica saber y poder, porque ese cuerpo que se quiere capturar es un cuerpo leído desde un determinado saber que lo nombra 
en tanto una potencial amenaza y puede operar sobre él eliminándolo por la propia amenaza que pudiera comportar; es decir, la visibilidad viene ya impregnada de un saber, acontece desde él, a través de él.

Todas las alusiones anteriores a la mirada ilimitada que el dron compone están encaminadas, en última instancia, a activar procesos de captura que operan en un doble plano: captura visual de personas, de prácticas, de lugares, de movimientos, pero también una captura en el sentido cinegético de cobrarse una pieza, de cazar personas (Chamayou, 2010), quienes encarnan una amenaza: ver para capturar.

Cabe resumir, entonces, que la vigilancia securitaria alude a un tecnosaber que impregna la visibilidad del dron; mientras tanto, la función necropolítica irrumpe como la manifestación más evidente del poder que encierra el dispositivo drónico en su acepción bélico-policial. Se interrogará enseguida esa vigilancia securitaria para proceder, después, sobre su dimensión necropolítica.

\section{El dron y la vigilancia securitaria para detectar la amenaza}

Uno de los efectos asociados al discurso de la fascinación fetichista que impregna al dispositivo drónico es su desligamiento de cualquier tipo de antecedente histórico, como si fuese una novedad radical que no se reconoce en ningún pasado. Sin embargo, del mismo modo en que es necesario poner de manifiesto la topología compleja que actualiza el dron, también sería esencial tener presente que si bien se está ante un dispositivo tecnocientífico dotado de unas características propias e inéditas, hay todo un bagaje sociohistórico que acompaña al dron, unas prácticas y unos discursos cuyo desbroce permitiría mostrar las conexiones del dron con otros dispositivos del pasado.

En las acertadas palabras de Wall y Manahan (2011:241):

Los drones son una combinación de lo nuevo y lo viejo: una nueva vigilancia aérea y un sistema de matar con capacidades no ofrecidas anteriormente por las formas convencionales del poder aéreo, que se ponen en relación con una antigua visión cósmica del dominio aéreo a través de la visión, la verticalidad y la velocidad tecnológica.

Desde este planteamiento cabe ahondar en la idea antes aludida de captura, en el campo de relaciones de saber-poder que la atraviesan y confluyen en la irrupción del dispositivo drónico.

Cabe afirmar así que el dron acontece como la última plasmación de un proceso de larga duración, concernido con el intento por capturar el dominio del espacio aéreo y someterlo a una lógica de control que posibilite un ordenamiento tanto de lo que sucede en el aire como de las geografías ubicadas en la verticalidad del espacio aéreo controlado. Del mismo modo 
en que sería posible rastrear los procesos históricos a través de los cuales se han establecido mecanismos de codificación de la tierra y el mar, procesos de territorialización mediante los que se pretendía reglamentar la producción simbólico-material de esos espacios y los usos y prácticas sancionados normativamente (Deleuze y Guattari, 1988), el aire, más allá de una retórica de sensación de libertad, ha estado igualmente subsumido en lógicas territorializantes conducentes a su apropiación y control.

Aquí se tendría lo que Weizman (2002) ha denominado de forma sugerente "política de la verticalidad" y en donde, históricamente, el poder óptico se revela como un poder aéreo que acompaña la colonización (Adey, 2010) y la vigilancia de las fronteras y los territorios, tal y como expone con nitidez Arteaga-Botello (2016) en su análisis del desarrollo del dron en el contexto de América Latina. Episodios históricos como los acontecidos en la guerra de Vietnam (Shaw, 2016) o en la zona que se conocía como Arabia, dominada por el imperio británico (Satia, 2006), evidencian todo un intento por ejercer un poder aéreo, el cual incluía la observación y el dominio militar sobre unas determinadas geografías.

Desde este trasfondo, el dron bélico emerge lógicamente como consecuencia de todo un proceso de desarrollo tecnocientífico, pero también impregnado de un pasado colonial que es preciso no olvidar:

El poder aéreo ha sido siempre un poder policial. Tenemos que leer al dron, en consecuencia, no tanto como una nueva forma de tecnología militar que de un modo u otro posibilita adentrarse sigilosamente en los espacios civiles para propósitos policiales sino, por el contrario, como una continuación de la lógica policial inherente al poder aéreo desde sus inicios (Neocleous, 2014: 156).

Lo que algunos autores han denominado dronificación de la violencia estatal (Shaw y Akhter, 2014), para aludir tanto a un impulso de la vigilancia securitaria como a una redefinición de lo bélico, se debe poner en el contexto de un proceso de larga tradición histórica (Kaplan, 2006; Neocleous, 2014; Shaw, 2016; Wall y Manahan, 2011), donde la vigilancia y lo militar, lo policial y lo bélico, actúan de un modo entrelazado en una suerte de equilibrio móvil que, según las circunstancias y los espacios en los cuales opera, adquirirá una u otra forma, ejercitando o no, su potencialidad necropolítica.

Resulta iluminador -a manera de ejemplo e incidiendo ya más directamente en el presente que se habita- adentrarse en todos los pormenores del cuidado informe Eurodrones Inc. que realizan Hayes et al. (2014). Ahí se detalla el modo como se ha ido impulsando la investigación sobre los drones en el marco de los proyectos de investigación financiados por la Unión Europea, y también se pone de relieve la propia retórica que impregna al dron en el ámbito 
institucional y de la investigación. En un contexto político-económico donde se va progresivamente apuntalando la investigación tecnocientífica concernida con políticas de seguridad y la idoneidad de que esa investigación pueda tener un doble uso en lo militar y en lo civil, el dron irrumpe de forma creciente como un ensamblaje estratégico que moviliza un mayor número de instituciones, fondos, tecnologías y discursos securitarios.

La proyección más significativa alude quizás al impulso que se está haciendo de los drones en el marco del sistema de vigilancia fronteriza europea (Eurosur), gestionado por Frontex (la agencia encargada del control fronterizo de la Unión Europea) y los apoyos que todo ello recibe de la Agencia de Defensa Europea. Cuestión sin duda central porque, como más adelante se expondrá con mayor detalle, el dron irrumpe como un dispositivo especialmente concernido con las fronteras: por una parte, para vigilancia de las fronteras estatales vigentes frente al flujo migratorio; pero también, por otra, como dispositivo que traspasa fronteras, dando lugar a una reactualización del poder soberano móvil que busca detectar la presencia, allí donde sea preciso, de la amenaza.

En este escenario que evidencia sinergias civiles y militares, el dron emerge a modo de la actualización de un deseo de visibilidad omnisciente y una práctica performativa de vigilancia ininterrumpida que se teje material y discursivamente; desde ahí, el dron irrumpe como garante de protección frente a los peligros que esa vigilancia prevé y detecta.

Lo securitario, núcleo categorial de la sociedad burguesa (Neocleous, 2010) y que pervive en sus mutaciones como ropaje de un neoliberalismo que distribuye de manera desigual amenazas y riesgos, expresa aquí toda su centralidad y potencia al ser el punto de encuentro entre lo simbólico (protección y defensa) y lo tecnológico (desarrollo de un poder óptico), el nodo que se propaga de modos diversos y subyace e impregna la producción y legitimación del dron bélico-policial. Por todo ello, cabe decir que el dron actúa como un dispositivo securitario a través del cual se pretende regular el orden de los acontecimientos, un entramado multidimensional en donde una trama simbólica-tecnocientífica-política-económica-jurídica intenta dar cuenta de lo que sucede y actuar frente al magma de una sospecha creciente que, por utilizar la imagen borgiana, se (con)funde con el territorio.

Lógicamente, se debe ubicar el ethos vigilante que reproduce el dron en el campo de una vigilancia ininterrumpida, la cual ha adquirido en los últimos años una creciente notoriedad, acentuada sin duda tras las declaraciones de Snowden (Lyon, 2015), y que posibilita el rastreo de las comunicaciones y el acceso a dispositivos informáticos, con el fin de analizar lo ahí contenido, 
mediante complejos programas de acopio y análisis de la información que dan, a la postre, todo un entramado de Big Data.

No hay aquí posibilidad alguna de reconocerse en un presente asegurado y libre de riesgos (siempre está la posible amenaza latente que en cualquier momento pudiera emerger), con lo que la vigilancia securitaria que reproduce el dron en su proyección área, en concomitancia con otros mecanismos tecnocientíficos de vigilancia que funcionan en paralelo, acaba por tornarse estructural, recreando una geografía móvil de lo securitario que se superpone a todo rastro de sospecha, y a través de la cual no se deja de producir datos, una cantidad ingente de matrices de datos y metadatos cuyo propio análisis exige la demanda de más datos.

Nos precipitamos así en una sociedad expuesta (Harcourt, 2015), abierta y subsumida en la vigilancia, donde, como bien apunta Shaw (2016), la forma de proceder no se asienta tanto en la certeza de que exista una amenaza ya detectada susceptible de activarse, sino en un modo de actuar que ha asumido y naturalizado la potencial presencia de la sospecha como mecanismo a través del cual se llevan a cabo operaciones de vigilancia.

El ejemplo más evidente de esto en el dron bélico ha sido el desplazamiento que se ha operado, por parte de Estados Unidos, desde la política de asesinatos selectivos de personas peligrosas (lo cual se denominaría personality strikes), consideradas de alto valor estratégico por su papel relevante en grupos terroristas, a una política de la sospecha generalizada, llevada a cabo bajo el mandato de Obama, donde el objetivo ya no es una persona conocida y previamente localizada, sino lo que habrá de denominarse a pattern of life, un determinado patrón o modelo de vida que, por sus rasgos y por el modo como es analizado, acaba siendo leído en clave de amenaza, como un potencial riesgo inminente sobre el cual se actúa mediante un ataque que, en este plano, pasa ya denominarse signature strike; un ataque militar no necesariamente sobre alguien conocido sino sobre la anomalía misma:

El objetivo principal de estos dispositivos de vigilancia persistente no es tanto seguir la pista de individuos ya conocidos como ver emerger elementos sospechosos denunciados por sus comportamientos anómicos, pues este modelo de información está "fundado en la actividad", es decir, sobre un análisis de las conductas, antes que sobre un reconocimiento de identidades nominales (Chamayou, 2016: 47).

El cambio cualitativo que esto opera es sin duda evidente y contiene un sustrato informacional por tener en cuenta: al dispositivo permanente de vigilancia le sigue un análisis reiterado de la matriz de datos disponible, cuya dimensión requiere el uso de complejos algoritmos a través de los cuales se procede a establecer relaciones y conexiones, con el fin de poder detectar y nominar aquellos rastros susceptibles de convertirse en algo amenazante. 
El algoritmo deviene el sustrato material-computacional desde el cual se leen las conductas de las personas, el modo como está pautada su cotidianidad, buscando la posible huella de una sospecha, el signo de que algo se ha salido de lo normalizado. Por tanto, este saber vigilante hipertecnologizado confiere así al algoritmo la función determinante de establecer un fondo informacional de conexiones, similitudes, pautas o modelos de comportamiento dónde buscar incansablemente una anomalía; todo ello vendrá entonces a constituir la trama desde la cual se identifican, examinan, validan y nominan los posibles objetivos para los drones.

La "guerra algorítmica” (Amoore, 2009) se revela como el saber experto que vehicula el conflicto, confiriéndole, en las decisiones adoptadas (ya sea para vigilar una determinada zona o para llevar a cabo un ataque), el ropaje de una racionalidad tecnocientífica que identifica en la maraña de datos obtenida un quiebre amenazante de la normalidad, el momento en el cual la mirada omnisciente encuentra algo que permite articular un relato en donde ya se puede contar el modo como están relacionados un conjunto de datos que permanecía desconexo. El algoritmo se revela entonces como el conector tecnopolítico ubicado en el terreno intersticial de la bifurcación que remite a la norma y a la anomalía, la huella de un ethos vigilante que quiere rastrear y tener localizado en todo momento la presencia de la sospecha.

Pero en esto, una vez más, la tecnificación de la decisión intenta despolitizar la decisión tomada, como si esta no viniese ya impregnada de valoraciones político-simbólicas hacia quienes encarnan potencialmente el peligro. El algoritmo, por ello, realiza, de forma simultánea, una doble función. Por una parte construye la normalidad y, por otra, nombra la anomalía respecto a esa normalidad previamente construida. No obstante, y como bien precisa Amoore (2009), esta normalidad no responde al esquema de un régimen disciplinar ya constituido y que se aplica de una manera más o menos estable en un espacio cerrado; se está ante una normalidad dúctil, la cual ha de ser interpretada en sus variaciones y en los grados de desviación que comienzan a ser interpretados como un riesgo.

Lo relevante aquí es que la interpretación de la situación incorpora efectivamente el conocimiento tecnocientífico del algoritmo, pero también todo un saber experiencial sobre una geografía y los sujetos que la habitan, con lo cual toda una dimensión simbólico-cultural en torno a la amenaza y los sujetos que la encarnan está presente ya de un modo inextirpable en el momento de tomar una decisión. Se mira - como se dijo antes-desde el cuerpo, y ello impugna cualquier atisbo de mirada neutral. 
En este punto, el dispositivo drónico se prepara para dar cuenta del enemigo, para capturarlo, pero no solo ya como cuerpo ubicado en una imagen sometida a seguimiento, sino como objetivo que puede y acaso debe ser eliminado. Lo que Chamayou (2010) ha llamado sugerentemente poder cinegético irrumpe aquí como el hacer necropolítico de la captura; una captura que en el marco de la llamada "Guerra contra el Terror" iniciada (o acentuada) tras el atentado a las Torres Gemelas adquiere sus plasmaciones más significativas, en la producción del sujeto torturable (Mendiola, 2014) y el sujeto matable (Pugliese, 2016), ambos subsumidos en una captura que imprime en la subjetividad sobre la cual se proyecta el desprecio que borra la posibilidad del reconocimiento del otro, la empatía que habría de socavar la imposición de dolor y sufrimiento.

El sujeto torturable y matable son manifestaciones específicas de un fondo común, que es el sujeto despreciable, modos diversos en los cuales la captura se abalanza sobre una vida que no es reconocida como tal, vidas despojadas del derecho a seguir viviendo, vidas inmersas en una lógica securitaria de la excepcionalidad que las sustrae de toda garantía legal. El dron, en el marco de esta genealogía, opera como un dispositivo cinegético de captura del sujeto matable y es por ello que la producción de la (exposición a la) muerte se adhiere así, como rasgo constitutivo, al dispositivo drónico.

\section{El dron y la necropolítica fronteriza}

En el presente recorrido sobre el dispositivo drónico de carácter bélico, se ha partido de un deseo de visibilidad omnisciente que se precipita en una vigilancia securitaria sobre lo que queda consignado como anomalía. Ahora se ahondará en el tercer y último eje de esta reflexión: el modo como se actúa sobre esta anomalía, partiendo de que ello, mediante el uso de los drones, ha comportado una significativa redefinición de la práctica bélica. Es aquí donde irrumpe un hacer necropolítico, el cual es necesario interrogar y exponer.

En primer lugar, habría que constatar que en el marco de esa redefinición de la lógica bélica, el objetivo no pasa tanto por la ocupación militar efectiva de un territorio cuanto por el intento de incidir en los procesos de ordenamiento de esos territorios y, más conectado a la presente línea de argumentación, por la necesidad de detectar y eventualmente eliminar la figura del enemigo alli donde esté; el derecho de conquista queda transmutado en un derecho de persecución, de búsqueda (Chamayou, 2016). 
La centralidad de este último apunte es determinante porque el enemigo compone una geografía móvil que no responde ya a una compartimentación geográfica-estatal del conflicto. El entramado bélico-policial articula una línea movediza que actúa en paralelo a la geografía móvil del enemigo, superando por ello la fijación inmóvil de la frontera estatal, y dando lugar a territorios donde se trenzan complejas relaciones entre soberanía, tierra y población (Elden, 2009).

Se entra así a un escenario marcado por una soberanía que compone sus propios territorios en función de los movimientos que la vigilancia securitaria le conmina a efectuar. La idea de enfatizar esto es que el dispositivo del dron conforma un territorio que opera a través de una política de la verticalidad radicalmente dinámica. Toda la temática de la redefinición de lo fronterizo donde se acentúa su heterogeneidad e implosión (Mezzadra y Neilson, 2013; Vaughan-Williams, 2012) irrumpe con una indudable notoriedad, porque, en última instancia, lo que aquí se está dilucidando es una redefinición profunda de los anteriores marcos de la geografía estatal, en un contexto de soberanía móvil que arrastra en sus desplazamientos una vigilancia securitaria, la cual se autoconfiere la posibilidad de dar muerte a la presa. El dispositivo drónico debería leerse, por eso, como una práctica radicalmente fronteriza, un ejercicio de des-re-territorialización, donde está en juego la producción de un espacio soberano en el cual se decide impune y arbitrariamente sobre la vida y la muerte.

Todo lo dicho antes en torno a la visibilidad que se quiere omnisciente y a la vigilancia securitaria que anhela capturar la amenaza, viene a confluir en el vuelo del dispositivo dron en tanto práctica fronteriza que decide sobre la vida y la muerte. Y es aquí donde irrumpe una necropolítica específica, una redefinición del viejo poder soberano enunciado por Foucault (2003), el que, precisamente, estaba concernido con el “hacer morir y el dejar vivir”. Más allá de una sustitución de ese régimen de poder por otros que habrán de quedar conceptualizados en torno a lo disciplinar y lo securitario, el mismo Foucault (2003 y 2006) subraya la importancia de indagar en el modo como anteriores regímenes de poder perviven, en su propia mutación, en posteriores contextos sociohistóricos, dando lugar a la especificidad de cada geografía y temporalidad.

En ese sentido, la pregunta por la producción de la muerte, central para el poder soberano, lejos de ser algo del pasado, es una cuestión con potencialidad para indagar en la actualidad del presente, teniendo en cuenta que esa producción de muerte puede devenir por el ejercicio de una acción directa, pero también por una manera de ordenar lo social que desencadena una exposición a la muerte (Foucault, 2003). 
Aún cuando no haya posibilidad de explorar ahora sus diferencias, sí es necesario añadir que los desarrollos teóricos que, de una forma u otra, han optado por poner en relación reflexiones en torno a la producción de vida y la producción de (la exposición a) la muerte, adquieren en el marco de esta investigación una centralidad indudable, al permitir encontrar un acomodo para la especificidad del dron bélico. Asimismo, es esencial destacar ahí la potencia de la propuesta de Mbembe (2011) sobre la necropolítica, en la medida en que incide en toda una deriva colonial que no está desarrollada en Foucault (2003) y es indisociable de la producción de muerte vinculada con el dispositivo drónico aquí analizado.

La imbricación entre la necropolítica y el dron se enmarca en el contexto de una política de defensa que busca protegerse de quien ha quedado definido como una amenaza, una suerte de respuesta inevitable subsumida en los parámetros de una doctrina jurídica que alude a la presencia de un peligro inminente (Gregory, 2015), en tanto legitimación del empleo de la fuerza militar para cometer asesinatos selectivos o bombardeos a anomalías vivientes. Pero no se está ya ante una circunstancia específica, un momento y espacio susceptible de ser acotado en cuanto a la asunción de una excepcionalidad, ubicada dentro y fuera del derecho según la aproximación agambeniana, la cual habría de permitir responder en la forma como se considere necesario ante las amenazas detectadas.

Esta excepcionalidad dará lugar a lo que Butler (2006) denomina soberanía espectral, una reapropiación del viejo derecho del poder en el marco de una lógica de gubernamentalidad securitaria, que asume la producción de muerte de un modo contingente e impune; esa excepcionalidad subyace, en definitiva, a las reconfiguraciones del poder bélico-policial, para gestionar el riesgo y la captura del enemigo (Chamayou, 2010; Neocleous, 2014).

Y desde ahí el dron bélico dibuja los contornos de una línea movediza, frágil, evanescente, línea de captura que se despliega y repliega cuando sea necesario para crear una geografía de la excepcionalidad, que ejercita su potencialidad necropolítica:

Los algoritmos del dron, en otras palabras, descomponen los sujetos civiles en "formas de vida" (con un sustrato biológico) sospechosas que son posteriormente recompuestas, por los operadores de drones, en objetivos matables. El funesto ataque del dron cumplimenta, en última instancia, la descomposición literal de lo que eran sujetos humanos en sustancia necropolítica (Pugliese, 2016: 12).

Una vida, en definitiva, inmersa en una deshumanización tecnologizada que detecta coordenadas móviles en las pantallas, una vida vigilada, rastreada, eliminable, silenciada, una vida, por todo ello, radicalmente expuesta 
a la muerte. Este es el brutal sello de la necropolítica que ha quedado ya adherida, como elemento estructural, al dispositivo drónico.

Cabe añadir que esa línea movediza -la línea de combate frente al enemigo - ha quedado sustraída del peligro de exposición a la muerte que el propio escenario del combate comportaba tradicionalmente. El dispositivo drónico moviliza un poder necropolítico, pero él mismo se oculta tras su poder óptico omnisciente, componiendo así un contexto bélico donde la batalla (para unos) se libra en una pantalla y donde el soldado se transmuta en un piloto ubicado en una base militar estadounidense a miles de kilómetros de la zona observada.

La enorme distancia geográfica se contrapone extrañamente a esta proximidad visual, en donde la indudable relevancia de lo que ahí se suscita (la posibilidad de vivir o morir) ha quedado ya subsumida en todo un saberhacer, que ha naturalizado y asumido la función necropolítica del dron, a través de la propia banalización de la violencia securitaria.

En este contexto, Pugliese (2016) ha llamado de forma certera la atención sobre las sinergias que se desatan entre el pilotaje del dron y el uso de videojuegos en espacios como los casinos. Sinergias que remiten a la propia organización del espacio (las pantallas, los mandos, los asientos), pero también al propio hecho de que el mismo pilotaje del dron se pueda concebir como un videojuego (dándose el caso, como apostilla Pugliese, de que incluso en los propios tiempos muertos de realización de la vigilancia, los pilotos de drones, sin moverse de donde están, se ponen videojuegos para amenizar la espera), conformando así una suerte de "mentalidad de videojuego", la cual se ha habituado a experimentar lúdicamente lo bélico y ha naturalizado el hecho de dar muerte a figuras que representan lo humano. Todo un trasfondo que de un modo u otro está presente en el momento de visualizar figuras reales en la pantalla y de ejecutar disparos que matan a esas figuras.

Y es cierto, como bien matiza Gregory (2012), que hay diferencias notorias entre el videojuego y la práctica efectiva de dirigir un dron (entre las cuales cabría enfatizar la dificultad para determinar efectivamente quién es combatiente y quién es civil, algo que el videojuego puede resolver sin problema), pero también conviene no olvidar esas interferencias en lo que tienen de un sustrato simbólico más profundo, que ha consolidado, partida a partida, la asunción de la violencia, la banalización de lo que supone matar una figura (real o ficticia) demonizada.

La cruenta línea de combate, donde históricamente se ha experimentado en la inmediatez de lo corporal el hecho de herir y dar muerte al enemigo (Bourke, 2008), se transmuta así en una línea movediza teledirigida que altera 
con profundidad la propia vivencia de lo bélico: el combatiente no tiene que "regresar a casa" tras su traumática experiencia bélica, porque el propio combate forma parte de su rutina cotidiana, y tras su jornada bélico-laboral volverá a su domicilio a retomar sus tareas domésticas.

Aquí se está en los inicios ya consolidados de una profunda redefinición estratégica, tecnológica, sensorial y discursiva de lo bélico. Una guerra necesaria para hacer frente a un enemigo difuso y amenazante, llevada a cabo a lo largo de una hipertecnologizada línea movediza guiada por un supuesto poder óptico omnisciente, que dice asegurar la precisión de la captura en su ejercicio necropolítico. La guerra de precisión se torna en una guerra quirúrgica que posibilita detectar y erradicar las metástasis detectadas, los movimientos de cuerpos tumorales que portan el peligro.

Esta (ilusión de) precisión legitimaría así un modo de proceder que supuestamente habría de eliminar todo daño colateral, con lo cual la producción de muerte que el dron activa en su plasmación militar se proyecta hacia una necroética, donde lo que ahí se suscita ya no es tanto el buen morir sino el buen matar (Chamayou, 2016); es decir, un matar que no expone a quien mata (porque quien mata no está presente en el acto de matar, es un matar a distancia que erradica el riesgo de la intervención directa en la acción bélica) y un matar que sólo mata a quien ha devenido matable (la anomalía convertida en un objetivo). Esta necroética cumplimenta por tanto una redefinición humanitaria de lo bélico, sustentada en la precisión tecnocientífica de su mirada omnisciente.

La tecnoguerra limpia, proyectada sobre un blanco claramente delimitable, sin (apenas) víctimas civiles, envuelta en un clima de opacidad y adaptada a la geografía móvil de la presa, vendría entonces a apuntalar ese buen matar que comienza a ser naturalizado como una nueva forma de proceder bélico: una guerra aceptable de baja intensidad mediática, sustraída de toda responsabilidad penal que se presenta, en definitiva, como la guerra admisible, como la guerra necesaria que el dispositivo drónico ha hecho, por fin, posible y tolerable.

El buen matar es, por ello, el punto culminante del fetichismo tecnocientífico del dispositivo drónico, el régimen de verdad que cumplimenta su absoluta descontextualización: por una parte, borra todo el régimen geográfico-corporal que posibilita la mirada omnisciente y, por otra, asume la violencia supuestamente quirúrgica que desencadena la necropolítica incorporada a la vigilancia securitaria. Pero es este régimen de verdad lo que debe ser impugnado, con el fin de aprehender aquello que se suscita en la producción $\mathrm{y}$ vivencia de la guerra. 
En este sentido, el discurso de la exactitud habría de ser analizado no tanto como huella de la objetividad tecnocientífica sino como una objetivación que a través de todo un proceso de traducciones y mediaciones (Latour, 2008) pretende construir y mantener un mundo discursivo-material, donde se debe relegar y silenciar aquello que no encaja. Y lo que no encaja aquí es la muerte de la población civil, esos mal llamados daños colaterales que vienen con toda guerra.

Aspectos como el hecho de que la exactitud en la erradicación del blanco no impide necesariamente que ese blanco-amenazante pueda estar acompañado de civiles, que se destruyan infraestructuras necesarias para la vida civil de una comunidad, que haya errores en el suministro de información por parte de los servicios de inteligencia o que la imagen visualizada en la pantalla pueda ser leída de un modo equívoco, vendrían a designar los elementos que socavan el discurso quirúrgico de la precisión (Zehfuss, 2010), las huellas que la necropolítica del dispositivo drónico va dejando a su paso.

La propia peculiaridad de la guerra drónica y la opacidad que la envuelve hace difícil saber lo que ocurre en los espacios atacados, pero si uno se atiene a los datos proporcionados por The Bureau of Investigative Journalism (2017), una fuente que se ha convertido en referencia a la hora de fundamentar los impactos de los ataques de drones, tan solo en Afganistán habrían muerto desde 2015 y hasta 2017 , entre 2.837 y 3.833 personas como consecuencia de 3.005 ataques documentados.

En un sentido más profundo, cabe apostillar que si bien el poder aéreo reproduce, para legitimar su propio funcionamiento, la noción de un enemigo al cual hay que vigilar y eventualmente eliminar, en su propia operatividad acaba por tornar irrelevante la distinción entre civil y combatiente, pues su objeto es la destrucción de una vida leída en clave de amenaza al margen de la destrucción civil que ello habría de comportar. La categoría de civil emerge, por ello, retrospectivamente, como denuncia de la vida que ha sido eliminada y que solo desde su muerte misma irrumpe como vida civil que no debía haber sido matada (Neocleous, 2016); esa vida en vida era una vida sustraída de una lógica de reconocimiento: no ya una vida matable (no es, en sentido estricto, la vida del enemigo, del sospechoso), sino una vida prescindible, una mera impresión visual en una pantalla que designa una vida no merecedora de ser protegida.

Frente a esta lógica necropolítica, frente a toda fascinación por el dron y su popularización mediática (por ejemplo, la multipremiada serie televisiva Homeland), deviene necesario la producción de otro régimen de visibilidad, donde se dé cuenta y se muestre la violencia desplegada por el dispositivo 
drónico. Adquieren aquí relevancia iniciativas como la del proyecto fotográfico de Noor Behram (Delmont, 2013; Walters, 2014), en el cual se recoge el escenario que dejan atrás los drones tras haber bombardeado un lugar; un escenario de destrucción y ruinas donde se fotografían igualmente las personas muertas, fotografías que exponen los rostros en primer plano de las vidas prescindibles, de esos sujetos negados que sólo vemos porque ya no existen.

$\mathrm{Y}$ a ello se suman los cuerpos que se rompen, que se desmiembran y quedan convertidos en un amasijo de carne y hueso, impidiendo su reconocimiento, la posibilidad misma de tener los restos identificados para su posterior entierro. Proyecto que expone la necropolítica y se expone a los riesgos que implica dar cuenta de esa violencia.

Pero también, en esa exposición de lo necropolítico, habría que tener presente las biopolíticas emanadas de la vigilancia securitaria que alteran las formas de vida existentes en aquellos espacios donde la sospecha del ataque ha quedado ya incrustada en la cotidianidad. Como sugiere Shaw (2016: 126): "La lógica biopolítica del ataque del dron no es simplemente la muerte: es el ordenamiento y el control del mundo de vida”.

Los relatos recogidos en informes como Living under drones (International Human Rights and Conflict Resolution Centre y Global Justice Clinic, 2012) y Death by drone (Open Society Justice Initiative, 2015), realizados en Pakistán y Yemen, respectivamente, muestran lo que supone vivir en una exposición a la muerte, la cual ha devenido cotidiana y que exige reformular sus prácticas cotidianas.

Todo ello se refleja en aspectos tales como los miedos existentes para atender a las víctimas de los ataques, pues ese lugar (como en alguna ocasión ha sucedido) puede volver a ser bombardeado, los efectos socioeconómicos de las destrucciones que dejan tras de sí los drones, los impactos en la salud mental, derivados de la inquietud que genera la posibilidad de poder ser atacado en cualquier momento, la supresión o alteración de todas aquellas actividades que generen la conformación de grupos, porque la agrupación misma puede ser interpretada como el encuentro de combatientes enemigos, aspecto este que ha modificado prácticas sociales como la asistencia a centros escolares, el encuentro con amigos, o algo tan importante a nivel simbólico como son los ritos funerarios.

Cabría concluir apuntando que, paradójicamente, la producción de otra visibilidad que evidencie el sustrato mendaz que compone el régimen de verdad securitario no designa solo lo que el modelo de guerra quirúrgica pretende ocultar y alejar del plano político-mediático; también es, y de un modo palmario, lo que el propio poder óptico no deja de ver, lo que el piloto 
del dron - a pesar de la distancia física respecto al objetivo que ha atacadopuede contemplar, esa destrucción causada que ahora, quizá con inquietante precisión, observa en su pantalla.

En el pasado, el piloto de aviones no veía la destrucción que sus acciones causaban; sin embargo, eso cambia sustancialmente en la redefinición de lo bélico que comporta el dron: el piloto del dron no corre riesgo, ve la figura que debe eliminar, acaso no se confronta con el rostro del sujeto matable/prescindible, pero ve lo que su acción desencadena, ve todo, acaso ve demasiado, y esas imágenes se las lleva consigo cuando regresa a su hogar tras su jornada bélico-laboral. La aparición de síntomas asociados al estrés postraumático en los pilotes de drones (Pugliese, 2016; Shaw, 2016) expone la ineludible corporalidad de lo bélico; el hecho de que esa violencia desplegada acaba experimentándose y sintiéndose en el propio cuerpo, incluso en ese cuerpo que sin estar en el campo de batalla tiene un acceso visual privilegiado a él.

\section{Conclusiones}

Enfatizar el sustrato tecnocientífico de la guerra quirúrgica de precisión o incluso el debate jurídico en torno al modo como los ataques de drones se acomodan a un marco normativo vigente (Gregory, 2015), supone a la postre sustraer a la propia guerra de los espacios y cuerpos que produce, como si la batalla que se contempla en la pantalla hubiera quedado desgajada de la geografía vital que recibe el impacto de los misiles. Lo bélico es siempre producción de muerte, pero también de espacios, de cuerpos, de formas de vida afectadas por la violencia infligida y es esto, en definitiva, lo que debería constituir el elemento central en torno al cual habría de pivotar la reflexión sobre el hacer performativo del dron: la destrucción que comporta la guerra quirúrgica, la vivencia de una violencia impune, la caracterización de lo bélico como un espacio sensorial atravesado por el temor al ataque, por la experiencia de los cuerpos deshechos (Gregory, 2015; Lujan, 2015; Shaw, 2016).

En consecuencia, la tecnovisión cenital militarizada debe ser confrontada en todo momento con lo que se desprende de ese poder óptico, con el hacer cruento de lo bélico, mostrando que el sueño omnisciente aludido por Foucault, con el que se iniciaba esta reflexión, el que ensalzaba el "proyecto de una visibilidad universal, que actuaría en provecho de un orden riguroso y meticuloso" (Foucault, 1989: 15), se revela, en el presente, como una distopía, donde el dispositivo bélico-policial que actualiza el dron produce territorios entre la producción de muerte y miedo. Solo desde ahí cabe la impugnación de la fascinación fetichizada que arrastra el ensamblaje maquínico del dron. 
Convergencia Revista de Ciencias Sociales, núm. 79, 2019, Universidad Autónoma del Estado de México

\section{Referencias}

About, Ilsen y Denis, Vincent (2011), Historia de la identificación de las personas, España: Ariel.

Adey, Peter (2010), Aerial Life: Spaces, Mobilities, Affects, Gran Bretaña: Wiley-Blackwell.

Amoore, Louise (2009), "Algorithmic war: everyday geographies of the war on terror", en Antipode, vol. 41, núm. 1, Reino Unido: Wiley. DOI: 10.1111/j.14678330.2008.00655.x.

Arteaga-Botello, Nelson (2016), "Política de la verticalidad: drones, territorio y población en América Latina”, en Región y Sociedad, año XXVIII, núm. 65, México: El Colegio de Sonora.

Bal, Mieke (2016), Tiempos trastornados. Análisis, historias y politicas de la mirada, España: Akal.

Blackmore, Tim (2005), “Dead slow: unmanned aerial vehicles loitering in battlespace”, en Bulletin of Science, Technology \& Society, vol. 25, núm. 3, Estados Unidos: Sage.

Bourke, Joanna (2008), Sed de sangre. Historia intima del combate cuerpo a cuerpo en las guerras del siglo $X X$, España: Crítica.

Butler, Judith (2006), Vida precaria, Argentina: Paidós.

Chamayou, Gregoire (2010), Las cazas del hombre, España: Errata Naturae.

Chamayou, Gregoire (2016), Teoria del dron. Nuevos paradigmas de los conflictos del siglo $X X I$, España: NED Ediciones.

Crary, Jonathan (2008), Las técnicas del observador. Visión y modernidad en el siglo XIX, España: Centro de Documentación y Estudios Avanzados de Arte Contemporáneo.

De Certeau, Michel (1996), La invención de lo cotidiano, México: Universidad Iberoamericana.

Deleuze, Gilles y Guattari, Félix (1988), Mil mesetas, España: Pre-Textos.

Delmont, Matt (2013), "Drone encounters: Noor Behram, Omer Fast and visual critiques of drone warfare”, en American Quarterly, vol. 65, núm. 1, Estados Unidos: Johns Hopkins University Press. DOI: 10.1353/aq.2013.0002

Elden, Stuart (2009), Terror and territory. The spatial extent of sovereignity, Estados Unidos: University of Minnesota Press.

Foucault, Michel (1985), Saber y verdad, España: La Piqueta.

Foucault, Michel (1989), "El ojo del poder", en Bentham, Jeremy, Elpanóptico, España: Las ediciones de la Piqueta.

Foucault, Michel (1990), Vigilar y castigar, España: Siglo XXI.

Foucault, Michel (2003), Hay que defender la sociedad, España: Akal.

Foucault, Michel (2006), Seguridad, territorio y población, Buenos Aires: Fondo de Cultura Económica.

Frew, Joanna (2018), Drone Wars. The next generation. Disponible en: https://dronewarsuk. files.wordpress.com/2018/05/dw-nextgeneration-web.pdf [10 de mayo de 2018].

Gregory, Derek (2012), "From a view to kill: drones and late modern war", en Theory, Culture and Society, vol. 28, núm. 7-8, Reino Unido: Sage.

Gregory, Thomas (2015), "Drones, targeted killings, and the limitations of international law”, en International Political Sociology, núm. 9, Reino Unido: Oxford University Press. DOI: 10.1111/ips.12093.

Haraway, Donna (1995), Ciencia, cyborgs y mujeres, España: Cátedra Madrid. 
Harcourt, Bernard (2015), Exposed. Desire and disobedience in the digital age, Estados Unidos: Harvard University Press.

Hayes, Ben et al. (2014), Eurodrones Inc. Disponible en: http://www.statewatch.org/ news/2014/feb/sw-tni-eurodrones-inc-feb-2014.pdf [13 de enero de 2017].

Holmqvist, Caroline (2013), "Undoing war: war ontologies and the materiality of drone warfare”, en Millennium: Journal of International Studies, vol. 41, núm. 3, Reino Unido: Sage. DOI: 10.1177/0305829813483350.

International Human Rights and Conflict Resolution Centre (Standford Law School) y Global Justice Clinic (NYU School of Law) (2012), Living under drones: death, injury and trauma to civilians from US drone practices in Pakistan. Disponible en: http://chrgj. org/wp-content/uploads/2012/10/Living-Under-Drones.pdf [13 de enero de 2017].

Kaplan, Caren (2006), "Mobility and war: the cosmic view of US air power", en Environment and Planning $A$, vol. 38, Reino Unido: Sage.

Latour, Bruno (2008), Reensamblar lo Social, Argentina: Manantial.

Lefebvre, Henry (2013), La producción del espacio, España: Capitán Swing.

Lyon, David (1995), El ojo electrónico. El auge de la sociedad de la vigilancia, España: Alianza. Lyon, David (2015), Surveillance after Snowden, Estados Unidos: Polity.

Lujan, Enric (2015), Drones. Sombras de la guerra contra el terror, España: Virus.

Mbembe, Achille (2011), Necropolitica, España: Melusina.

Mendiola, Ignacio (2014), Habitar lo inhabitable. La práctica politico-punitiva de la tortura, España: Bellaterra.

Mezzadra, Sandro y Neilson, Brett (2013), Border as Method, or, the Multiplication of Labor, Reino Unido: Duke University Press.

Neocleous, Mark (2010), La fabricación del orden social. Una teoría critica sobre el poder de policía, Argentina: Prometeo Libros.

Neocleous, Mark (2014), War power, police power, Reino Unido: Edinburgh University Press.

Noys, Benjamin (2015), “Drone metaphysics”, en Culture Machine, vol. 16, Reino Unido: Open Humanities Press.

Open Society Justice Initiative (2015), Death by drone. Civilian harm by U.S. targeted killings in Yemen. Disponible en: https://www.opensocietyfoundations.org/reports/ death-drone [13 de enero de 2017].

Pugliese,Joseph(2016), "Dronecasinomimesis:telewarfareand civilmilitarization”,en Journal of Sociology, vol. 52, núm. 3, Reino Unido: Sage. DOI: 10.1177/1440783316655630.

Satia, Priya (2006), "The Defense of Inhumanity: Air Control and the British Idea of Arabia”, en The American Historical Review, vol. 111, núm. 1, Reino Unido: Oxford University Press.

Sekula, Allan (1986), “The body and the archive”, en October, vol. 39, Estados Unidos: MIT Press.

Shaw, Ian y Akhter, Majed (2014), “The dronification of state violence", en Critical Asian Studies, vol. 46, núm. 2, Estados Unidos: Taylor \& Francis. DOI: $10.1080 / 14672715.2014 .898452$.

Shaw, Ian (2016), Predator empire. Drone warfare and full spectrum dominance, Estados Unidos: University of Minnesota Press.

The Bureau of Investigative Journalism (2017), “Drone Wars: The Full Data”. Disponible 
en: https://www.thebureauinvestigates.com/stories/2017-01-01/drone-wars-thefull-data [17 de marzo de 2017].

Vaughan-Williams, Nick (2012), Border politics. The limits of sovereign power, Reino Unido: Edinburgh University Press.

Wall, Tyler y Monahan, Torin (2011), "Surveillance and violence from afar: The politics of drones and liminal security-scapes”, en Theoretical Criminology, vol. 15, núm. 3, DOI: $10.1177 / 1362480610396650$.

Walters, William (2014), "Parrhesia today: drone strikes, fearless speech and the contentious politics of security”, en Global Society, vol. 28, núm. 3, Reino Unido: Routledge.

Weizman, Eyal (2002), “The politics of verticality", en Open Democracy. Disponible en: https://www.opendemocracy.net/ecology-politicsverticality/article_801.jsp $\left[\begin{array}{ll}2 & \text { de }\end{array}\right.$ mayo de 2018].

Zehfuss, Maja (2010), “Targeting: precision and the production of ethics”, en European Journal of international Relations, vol. 17, núm. 3, Reino Unido: Sage. DOI: 10.1177/1354066110373559.

Ignacio Mendiola-Gonzalo. Doctor en Sociología y profesor de Sociología en el departamento de Sociología 2 de la Universidad del País Vasco. Sus principales líneas de investigación giran en torno al modo en que las relaciones de poder inciden en la producción de sujetos y espacios, dando para ello una especial importancia a la reflexión sobre la biopolítica y la necropolítica. Publicaciones recientes: Mendiola, Ignacio (2017), "De la biopolítica a la necropolítica: la vida expuesta a la muerte", en Eikasia, núm. 75, España: Universidad del País Vasco; Mendiola, Ignacio y Oviedo, Daniel [coordinadores] (2017), Relatos infames. Breves historias de crimen y castigo, España: Anthropos; Mendiola, Ignacio (2016), "El dispositivo de la captura: espacios y cuerpos bajo el signo de la excepcionalidad", en Athenea Digital, vol. 16, núm. 1, España. DOI: https://doi.org/10.5565/ rev/athenea.1739. 